\title{
Research on the Application of MOOC in University
}

\author{
Luo Yong \\ College of Science \\ National University of Defense Technology \\ Changsha, China \\ yngluo@163.com \\ Xie Zheng \\ College of Science \\ National University of Defense Technology \\ Changsha, China
}

\author{
Li Jianping \\ College of Science \\ National University of Defense Technology \\ Changsha, China
}

\author{
Zhou Guochang \\ College of Science \\ National University of Defense Technology \\ Changsha, China
}

\begin{abstract}
MOOC (Massive Open Online Courses) is a largescale online course platform. The global learners are able to learn college courses in it. At the same time, the universities are trying to apply it to make a great significance for the level of university education. This paper researches on the application of MOOC in university. Many problems have been found meanwhile the exploration and development of MOOC. It proposed some suggestions about how to correctly apply MOOC in university. We should be cautious about the course credits and MOOC certificates. The more resources of MOOC should be taken into the classroom. Teachers of college should be encouraged to learn in MOOC. If MOOC is in a proper education system, it will enrich teaching content, and develop a broader learning space for students.
\end{abstract}

Keywords-MOOC; credit; college education; application

\section{INTRODUCTION}

Massive open online courses (MOOC) are established by the universities in the network. The philosophy of MOOC is to enable global learners to get the chance to study the college courses by internet. At present, Coursera, Udacity, and Edx are the three major MOOC operators in the world.

MOOC develops rapidly in China. In May 2014, the project of "Chinese University MOOC" was launched officially, and it cooperated with iCourse. MOOC has aroused the enthusiasm of learning online in China. About130 thousand Chinese users registered on Coursera in 2013. The number ranks 9th in the world. But, it has reached 65 million in 2014. The extent of increasing is much more than other countries. Nowadays, one of eight people who learning on the MOOC are Chinese. There were more than 20 million times enrollments in iCouse in 2016.

MOOC has a series of teaching methods, including registration, video attendance, auditing, assignments, discussions, examinations, graduation, certificates, etc. MOOC brings the learners a new experience. They can get college education in their homes.

Though MOOC has been developed rapidly, it still has many controversies. Throughout the development of online education: from correspondence education to digital learning, to open courses (OER), to MOOC courses nowadays. It is the important problem in college how to use the online courses correctly. Many colleges began to try to let students gain credit by learn in MOOC, and let teachers take the MOOC resources into the classroom. These new teaching methods have made the college education enter a new field.

Now, whether MOOC certification equates to course credit was an important problem. But few people gave attention to it. Some researchers focused on MOOC learning behavior. Anderson [1] found some factors that influenced MOOC course learning through data mining. Adamopoulos [2] studied the factors and degrees that affect the retention rate of MOOC students. Gillani [3] analyzed the behavior of Courser's "Business Strategy Foundation" course 87000 students in the course forum and its relationship with the results of the analysis; Guo [4] studied the relationship between MOOC video editor and learning effects put forward the idea that how to record course videos in the scientific and reasonable way. From the perspective of Chinese MOOC learning behavior characteristics, Jiang[5] classified the learners so as to investigate the relationship between learning behavior and effect deeply.

From 2013 on, we have chosen a course on Cousera. The students can get credit for this course by learning on Coursera. It means that the students can earn the credit through MOOC. To 2017, this course has been opened a total of five times. We found some regulations in practice. This article will introduce this experience and propose methods to solve some problems, when MOOC was used in college.

\section{PROBleMs OF MOOC}

\section{A. The role of the University in MOOC is ambiguous.}

The university gives access to learning in universities through MOOC, this enables more students to learn and improve themselves. What can they gain from MOOC? Certification? If this certification is equal to college education, does it necessary to take part in the entrance examination of university? The entrance examination is regards as the threshold of learning in university and measures to select 
qualified students. It is meaningless when learning with no goal So, the certifications that gained through online courses have no credibility or authority. Therefore, university should act as the operator of resources.

\section{B. MOOC needs to establish reasonable standards.}

At present, the evaluation system of MOOC is not perfect. Evaluation index has not been systematically established, it can't provide effective guidance for students' learning. It is hard to find suitable and high-quality resources; all these factors result in the students having no idea about how to choose. A lot of time has been wasted.

A large number of repetitive courses with no features wasted the resources as well. It is high time that the access and elimination mechanism should be established. Only when the competition mechanism is introduced into MOOC, can the platform develop more healthily.

\section{MOOC is affected by economic interests.}

In the part of degree identification and training, MOOC has serious flaws. The assessment and credits identification are unfair. Fixed model, getting resource easily led to students copying answers without learning. On one hand, in the assessment system which has no institutional and technical assurance, driven by the power of credit, trying to avoid internet cheating relying solely on the integrity of learners is absolutely unscientific. Students tend to obtain credits by cheating; this can't be prevented by technology. This imperfect model induced students to obtain identification in violation of ethics.

On the other hand, the operators of MOOC tend to reduce the difficulty of testing and the standard, so as to attractive more students. For example, some of the courses on the Coursera require the accuracy of $35 \%$. The low standard can help more students obtain the certifications, but it reduced the quality. Driven by the interests, the value of MOOC is gradually reduced, and this led to the efficiency is limited.

\section{The mode of classroom teaching affects MOOC}

Currently, MOOC courses are taught by semesters, the organization is different from classroom teaching. In contrast, students in MOOC prefer to obtain knowledge rather than the certifications. The tests of MOOC are obstacles for students. What's more, the type of problems is pretty single. Due to the technical difficulties, most of the subjective items can't be used in MOOC. This makes current MOOC can't evaluate the real level of students comprehensively.

MOOC resources are updated by chapter, couldn't refined to each point. This reduced the efficiency and added more difficulties in learning. Students can't search with key point, and learn from one point to another. This affected the efficiency and effects. Selective learning and effective learning should play main parts in MOOC, the platform needs to be changed during the construction to accommodate the needs of online learners.

\section{HOW TO USE MOOC IN COLLEGE}

\section{A. The certification of MOOC shouldn't be affected by economic benefits.}

The open course that was opened by MIT(Massachusetts Institute of Technology) for global learners is the origin of MOOC. Professor Sebastian from Stanford, opened the course "Introduction to artificial intelligence". This course has brought about 160,000 learners. They come from 190 countries(regions). What's more, it has given birth to a Facebook group, an online discussion group and a large number of volunteer translators. The course was translated into 44 languages by volunteers. In the early time of MOOC, the resource operators aimed to share the curriculum resources. The knowledge and teaching skills were attractive. The certifications should act as the reward of honorable learning; try not to become tools for economic benefits. Taking the current technology into consideration, it's too early to provide credible certifications.

TABLE I. SOME MOOCS COMPLETION RATE

\begin{tabular}{|c|c|c|c|c|}
\hline University & Course title & $\begin{array}{c}\text { Enroll- } \\
\text { ment }\end{array}$ & $\begin{array}{c}\text { Completed } \\
\text { number }\end{array}$ & $\begin{array}{c}\text { Completion } \\
\text { rate }\end{array}$ \\
\hline MIT & Circuits and Elect & 155000 & 7157 & $4.6 \%$ \\
\hline Bichigan & $\begin{array}{c}\text { Internet } \\
\text { technology and } \\
\text { security }\end{array}$ & 45572 & 4595 & $10 \%$ \\
\hline Google & $\begin{array}{c}\text { Software } \\
\text { Engineering }\end{array}$ & 50000 & 3500 & $7 \%$ \\
\hline Duke & $\begin{array}{c}\text { Bioelectricity: a } \\
\text { quantitative } \\
\text { approach }\end{array}$ & 12725 & 313 & $2.5 \%$ \\
\hline
\end{tabular}

Therefore, the role of the university in MOOC is ambiguous. The identification of MOOC shouldn't be the concentration of university, or the resource of economic benefits. The university should develop the entity education and identify degrees; this status is beyond all doubt. If the university attracts learners to pay for their courses so as to obtain benefits, it will deviate from the right direction turn MOOC into tools for interests. Because of the high inputs, many MOOC are seeking for sponsorships from companies. Anyway, this will cause many courses rechargeable eventually. Now, the Coursera starting to charge students for lessons, which turns the potential learners away.

B. In the process of electing courses, the MOOC should turn credit-oriented into interest and demand-oriented, take efficiency as principle, avoid aspiring course completion rate deliberately.

Data shows that the most important motivation of choosing MOOC courses is pursuing knowledge shown in Fig.1.

At present, many well-known platforms and universities attempt to analyze data so as to improve the completion rate in MOOC. They start from the aspects of platforms structure, course contents, learning links, and video editors and so on. Data from Coursera shows that current completion rate of MOOC is basically maintained at $7 \%-9 \%$. Table 1 selects the 
number of courses and completion rate data for some of the well-known MOOC courses published on the web.

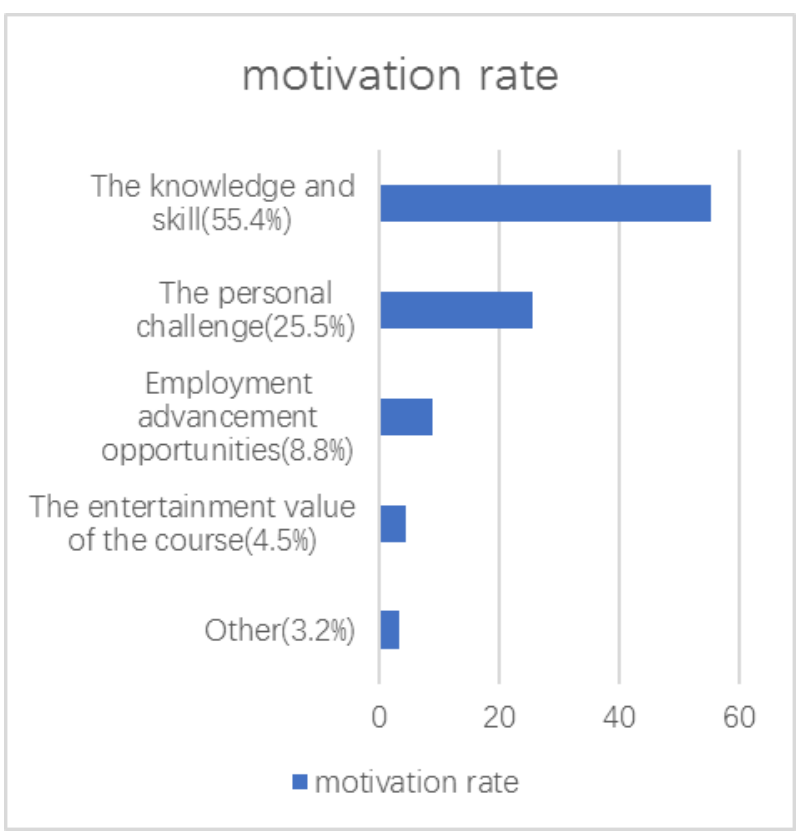

Fig. 1. Motivation for students to choose MOOC courses

It can be seen from the data that the efficiency of selforganization learning is limited. Because of the human nature, external supervision and management are essential. Working as an assistant of "Introduction to Mathematical Thinking", after 5 rounds of enrollment, the completion rate was $15.2 \%$.

TABLE II. MOOC COURSE COMPLETION RATE

\begin{tabular}{|c|c|c|c|}
\hline Year & Semester & Enrollment & Completed number \\
\hline 2013 & Fall & 24 & 3 \\
\hline 2014 & Fall & 60 & 8 \\
\hline 2015 & Spring & 14 & 2 \\
\hline 2016 & Spring & 7 & 3 \\
\hline 2017 & Spring & 30 & $?$ \\
\hline
\end{tabular}

\section{Teachers should use more MOOC}

Universities should encourage teachers to study in MOOC. Only the teachers start to learn in it, can the universities enhance the benefits from MOOC. MOOC courses are similar with research teaching, they only differ from each other in the aspects of elaborating problems and introducing the latest achievements. College teachers can enrich their teaching experience; improve teaching effect through learning MOOC courses. The efficiency can be deepened by sharing among teachers.

In 2013, as the person in charge for the five credits MOOC course, after 5 rounds of enrollment, we felt that the usage of MOOC was pretty limited. After some researches, we found that most of the students prefer to select courses they have been taught in their mother tongue. This makes the course turns out to be a professional course taught in foreign language. Students felt that what they received is worthless. In current university curriculum system, learning with no interest is useless. The universities have to face in developing scientific high-qualified students.

\section{MOOC resources should be taken into classroom.}

The MOOC resources can be introduced into classroom. Teachers can customize the resources to adapt classroom teaching. The quality teaching resources of the world-famous universities have entered the classroom properly. Hardware and software facilities should be ready. Teachers need some time to adapt to this new pattern. The classroom is synchronized with the world, the updating teaching content and skills makes the knowledge parallel the forefront of technological development and application.

\section{SUMMARY}

MOOC resources originated from the initial needs, sharing from superior educational institutions of popular teaching resources initiated the admiration among learners. However, with the further development of MOOC, its huge news benefits attracted a large number of domestic and foreign schools. On one hand, it caused great changes taking place in university teaching and curriculum constructions, many institutions didn't realize the impact of MOOC on university curricula and teaching. Wrong orientation has caused the waste of course funds, the faultiness of credit fostered academic dishonesty among students.

On the other hand, we should endorse the promotion of MOOC in classroom teaching. Through learning by teachers, we can introduce advanced teaching content into the classroom, attract the students and improve teaching resources in universities ultimately. Universities can combine MOOC resources like vide testing with classroom teaching. This will enrich teaching content, widen students' horizons and develop a broader learning space for students.

\section{REFERENCES}

[1] A. Anderson, D. Huttenlocher, J. Kleinberg, et al. Engaging with massive online courses, 2014:687-698.

[2] P. Adamopoulos, What makes a great MOOC? An interdisciplinary analysis of student retention in online courses. In Proceedings of the 34th International Conferenceon Information Systems, 2013, ICIS’13.

[3] N. Gillani. Learner communications in massively open online course. OxCHEPS Occasional Paper, 2013:53.

[4] P. J. Guo, J. Kim, R. Rubin. How video production affects student engagement: an empirical study of MOOC videos ACM Conference on Learning@ Scale Conference. ACM, 2014:41-50.

[5] Z. X. Jiang, Y. Zhang, X. M. Li, Learning Behavior Analysis and Prediction Based on MOOC Data, Journal of Computer Research and Development, 2015, 52(3):614-628.(In Chinese) 